\title{
An Online Library of Science-Based HIV Prevention Resources
}

\author{
Josefina J. Card*, Lucy Baden \\ Sociometrics Corporation, Mountain View, CA, USA \\ Email: *jjcard@socio.com
}

How to cite this paper: Card, J.J. and Baden, L. (2018) An Online Library of Science-Based HIV Prevention Resources. World Journal of AIDS, 8, 119-136. https://doi.org/10.4236/wja.2018.84010

Received: September 29, 2018

Accepted: November 2, 2018

Published: November 5, 2018

Copyright $\odot 2018$ by authors and Scientific Research Publishing Inc. This work is licensed under the Creative Commons Attribution International License (CC BY 4.0).

http://creativecommons.org/licenses/by/4.0/

\begin{abstract}
This paper introduces the online Sociometrics Social, Behavioral, and Health Sciences Library, an exciting new science-based resource for HIV/AIDS researchers, health educators, and clinicians. The over 400 products in the Sociometrics Library supplement the online publications-journal articles, books, reports, monographs-that have been the focus of scientific research libraries and publishers to date, both printed and online. Examples of the innovative science-based products that serve as the library's content include: Evidence-based interventions and programs (EBIs/EBPs) that evaluation research has shown to be effective in preventing HIV or its risky social and behavioral antecedents; primary research data and survey instruments; and interactive, multimedia training tools and courses to build HIV professionals' capacity to implement EBPs with fidelity and to cooperate with evaluators in the assessment of their effectiveness. A Scientist Expert Panel has guided and will continue to guide product selection and acquisition, ensuring the collection's continuing technical merit, research utility, and relevance for practice and policy. The Sociometrics Library aims to become the dominant online source of behavioral and social science-based HIV research by-products, operationally sustainable and able to stay up-to-date both from a technological and scientific perspective.
\end{abstract}

\section{Keywords}

HIV, AIDS, STI, Data, Instruments, Effective Programs, Evidence-Based Programs, Capacity Building Tools, Researchers, HIV Educators, HIV

Practitioners

\footnotetext{
\#The Sociometrics Social, Behavioral, and Health Sciences Library was developed with funding from the US National Institute of Minority Health and Health Disparities of the US National Institutes of Health (Grant No. R44 MD08851-02A1, Josefina J. Card, PhD, Principal Investigator). The authors are grateful to Drs. Anya Drabkin and Julie Solomon for their review of earlier drafts of this manuscript.
} 


\section{Introduction}

Despite global efforts to address the AIDS epidemic, HIV infection remains a significant problem, particularly for low-resource countries and US minority populations who are disproportionately carrying the HIV burden [1] [2] [3]. AIDS and related illnesses are the leading cause of death among women ages 15 to 49 globally, and the second leading cause of death for young women ages 15 to 24 in Africa [4]. While AIDS-related deaths have declined in some regions of the world, including eastern and southern Africa and North America, AIDS-related mortality has increased over the past decade in the Middle East and North Africa by 48\%, and in Eastern Europe and Central Asia by 38\% [4].

The populations most profoundly affected by the HIV epidemic include specific racial and ethnic minority groups, gay or bisexual men who have sex with other men (MSM), sex workers, and injection drug users. In countries across the world, HIV prevalence among key subpopulations is often substantially higher than among the general population [4]. In the United States, MSM accounted for $67 \%$ of new HIV infections and $83 \%$ of new infections in males in 2016 [5]. Among racial and ethnic groups in the US, African American and Hispanic men and women continue to be at higher risk of contracting HIV and yet have lower access to testing, prevention, and healthcare [2] [3] [6]. According to the CDC, the US Centers for Disease Control and Prevention, African Americans and Hispanics represent $30 \%$ of the US population but accounted for $69 \%$ of new HIV infections in 2016 [5].

\section{Evidence-Based Resources for Reducing HIV Transmission}

As a result, numerous programs and strategies have been developed across the globe to reduce HIV transmission and improve related outcomes [7] [8] [9] [10] [11]. Many such programs have been proven effective in changing behaviors, such as risky sexual or injection drug-related behaviors, that increase the probability of HIV transmission [12]-[17]. These effective programs are called evidence-based interventions (EBIs) or evidence-based programs (EBPs). Typically, EBPs not only inform participants with relevant knowledge and facts, but also teach new skills and give participants the opportunity to practice the skills with techniques like modeling, role-playing, and games.

Considerable research has demonstrated that select EBPs can decrease risky sexual and drug-use behaviors among populations heavily impacted by HIV/AIDS, including men who have sex with men [18] [19] [20]; injection drug users [21] [22]; young people [23]; and other high-risk populations. This is true in both high- and low-resource countries [24] [25] [26] [27] and across age groups such as youth and adults [28] [29] [30]. The success of EBPs in reducing HIV transmission among diverse populations, including high risk groups, has led organizations such as the CDC, NIH (the US National Institutes of Health), and WHO (the World Health Organization) to actively promote the use of EBPs [31] [32] [33] [34]. 
Many factors, however, continue to obstruct EBPs' wide dissemination and sustained implementation [33] [35] [36] [37] [38]. The most prominent barriers to EBP uptake and implementation are the lack of low-cost access to EBPs; the high cost and lack of availability of technical assistance; insufficient organizational capacity among community-based organizations implementing the EBPs; inadequate buy-in among staff; a lack of EBP fit with the personnel, money and time constraints of the organization; and limited knowledge about adaptation of EBPs to the local context [35] [38] [39]. Public health practitioners frequently report that they are stretched too thin. They are often expected to remain up-to-date on literature, seek out effective programs, perform program adaptations for their specific target audiences, and find other practitioners to share lessons learned from the field or exchange advice. Each step of the process requires a considerable time commitment from already busy health educators and providers, creating significant challenges.

Program adaptation to the local context can be a particularly weighty barrier, given the difficulty in determining how to adapt a program for new contexts while preserving the core components underlying the program's efficacy. However, program adaptation is itself an essential practice, as research has shown that programs must be tailored to appropriately address the cultural backgrounds, developmental levels, and community contexts of the target population [40] [41]. While adaptations are vital to an EBP's on going success, inappropriate modification of program components often reduces a program's efficacy and prevents it from changing behavior. Studies have shown that organizations frequently modify core program content [42] [43] [44]. Practitioners lack helpful, easily understood, science-based tools to help them apply the concepts of fidelity and flexibility to their work [45] [46]. Modifications are often made to adapt, alter or delete program content, scope, and/or delivery method to accommodate real-world circumstances such as time constraints, varying population or setting needs, or unavailability of organizational resources. Many such modifications are done without guidance for how the changes affect fidelity, core elements and desired outcomes [47] [48].

New tools and resources are required to bridge the gap between research and practice. There is a need not only for widespread identification and dissemination of EBPs, but also for tools and resources that support program fidelity, appropriate adaptation of EBPs to specific contexts, and program engagement.

Program evaluation is also of significance. Evaluation enables practitioners to understand why and in what areas their implementation of an EBP has succeeded or failed, the impact of each program component, and how to improve future implementations [49]. However, health practitioners often experience difficulty in evaluating their interventions because of factors such as a lack of research knowledge and training; difficulty developing questionnaires and other evaluation tools; lack of staff time to conduct evaluations; and low funding coupled with high evaluation costs [50] [51]. 
To address these challenges, Sociometrics Corporation has developed an online suite of research-based products and resources: the Sociometrics Social, Behavioral, and Health Sciences Library (https://www.socio.com/). This online library aims to address these challenges by expanding and updating the search for effective HIV prevention EBPs and HIV-related datasets; identifying EBPs that meet established effectiveness criteria; promoting easy dissemination and uptake of these EBPs across implementation settings, including low-resource regions; providing capacity-building tools that support program adaptation and fidelity; and enabling widespread evaluation of program efficacy by simplifying data collection, analysis, and sharing.

\section{Methods}

\subsection{Collection of Resources}

For over three decades, with funding from the NIH and CDC, Sociometrics has developed multiple topically-focused collections of evidence-based programs (EBPs), datasets, and capacity-building tools for health and public health professionals. Two of these collections-the HIV/AIDS Prevention Program Archive (HAPPA) and the Global HIV Archive (GHA)-contain EBPs that have been proven effective in reducing the sexual and drug-related behaviors that put one at risk of HIV/AIDS/STI transmission. The companion HIV/AIDS/STI Data Archive includes studies that provide descriptive and comparative data on the behavioral and social antecedents and consequences of HIV, AIDS, and sexually transmitted infections (STIs). Sociometrics has also developed capacity-building tools to aid in implementing, adapting, and evaluating EBPs.

\subsubsection{EBP and Data Collections}

Sociometrics' collections of EBPs and datasets were developed using a systematic process of identification (by Sociometrics staff), review and selection (by Scientist Expert Panels), acquisition (from the developer of the EBP or dataset) and processing for public use (by Sociometrics staff). A Scientist Expert Panel of four to six members was established for each topically-focused collection; panelists were researchers considered experts in the topic area. The Scientist Expert Panels developed resource selection criteria in conjunction with Sociometrics' staff of scientists. For EBPs, these criteria included the program's technical merit, replicability, and positive outcomes; the criteria for datasets included technical quality, substantive utility, relevance, and disciplinary balance. Candidate programs and datasets were then identified using extensive searches of relevant scientific literature, and briefing materials were prepared for each candidate resource. These briefing materials were provided to the Scientist Expert Panels, who assigned each resource a priority score for inclusion in Sociometrics' Library. Sociometrics contacted the developer(s), author(s), and/or investigator(s) of the selected programs or datasets to obtain permission to include the resource in the Sociometrics Library and to disseminate it for public use. Finally, obtained 
resources were packaged in a user-friendly way to facilitate replication in a new setting. For EBPs, packaging included a user's guide containing the curriculum and describing the evidence for its effectiveness; as well as all facilitator, participant, and evaluation materials needed to faithfully replicate and evaluate the program in a new setting. For datasets, the packaging included a user's guide describing the dataset's sample, data collection methods, and included variables. The raw data and analytic SAS and SPSS program statements were included, as were documentation files such as instruments, codebooks, and frequencies.

\subsubsection{Capacity-Building Tools}

To support the exemplary EBP and data collections, Sociometrics' scientists developed capacity-building tools and resources for ongoing education of HIV professionals. These tools aim to improve health practitioners' ability to implement EBPs with fidelity and cultural competence, evaluate them, and analyze the resulting data. Resources in the capacity-building collection include training modules focused on how to implement and evaluate specific EBPs; sexual health-related activities and exercises for use in middle and high school classrooms; behavioral skills training tools for developing and implementing culturally competent programs; and evaluation resource guides and tutorials.

\section{Results}

\subsection{Library Content}

As of this writing, the Sociometrics Social, Behavioral, and Health Sciences Library (https://www.socio.com/) consists of 90 evidence-based programs, 315 datasets, and 22 capacity-building tools for health professionals. HIV/AIDS is a significant focus of the Sociometrics Library: 65 evidence-based programs (Table 1), 29 datasets (Table 2), and 16 capacity-building tools (Table 3) are focused on HIV and HIV prevention. The collection continues to grow. For information on how to submit a science-based HIV dataset, EBP, or capacity-building tool to the Sociometrics Library, please go to https://www.socio.com/submissions.

\subsubsection{Evidence-Based HIV Prevention Programs}

Table 1 details the HIV-related evidence-based programs (EBPs) in the online Sociometrics Library. A wide variety of programs are included, focused on different countries, target populations, theories of change, and prevention approaches. All of the HIV EBPs have demonstrated a positive impact on reducing sexual and/or injection drug-related behavior(s) that put an individual at risk for transmitting or getting HIV/AIDS. The EBPs are presented in lesson-by-lesson sequence, with all facilitator and participant materials for each session included in view- and/or download-format.

\subsubsection{Exemplary Datasets}

The Sociometrics Library's datasets address a variety of topics including the incidence and prevalence of specific sexual behaviors; contraceptive and STI-preventive 
Table 1. Evidence-based programs (EBPs) in the Sociometrics Library with a topical focus on HIV/AIDS prevention.

\begin{tabular}{|c|c|c|}
\hline PROGRAM NAME & TARGET POPULATION $^{1}$ & BRIEF PROGRAM DESCRIPTION ${ }^{2}$ \\
\hline \multicolumn{3}{|l|}{ Global HIV EBPs } \\
\hline $\begin{array}{l}\text { Community-based Directly Observed } \\
\text { Therapy (C-DOT) Program }\end{array}$ & $\begin{array}{l}\text { HIV+ adults starting or who } \\
\text { recently started HAART }\end{array}$ & $\begin{array}{l}\text { Directly observed therapy to increase adherence to highly active } \\
\text { antiretroviral therapy (HAART) }\end{array}$ \\
\hline Entre Nous Jeunes & $\begin{array}{l}\text { Youth and young adults } \\
\text { ages } 10-25\end{array}$ & $\begin{array}{l}\text { A peer educator program to reduce STI/HIV and unintended } \\
\text { pregnancies }\end{array}$ \\
\hline$\underline{\text { HIV/AIDS Warriors Program }}$ & $\begin{array}{l}\text { Soldiers and other at-risk } \\
\text { populations }\end{array}$ & $\begin{array}{l}\text { A five-session HIV risk reduction program with monthly booster } \\
\text { sessions }\end{array}$ \\
\hline $\begin{array}{l}\text { Intervention with Microfinance for } \\
\text { AIDS and Gender Equity (IMAGE) }\end{array}$ & Impoverished women & $\begin{array}{l}\text { A ten-session gender and HIV training curriculum augmented by a } \\
\text { microfinance program }\end{array}$ \\
\hline $\begin{array}{l}\text { mDOT Program: For Individuals } \\
\text { Receiving Highly Active Antiretroviral } \\
\text { Therapy (HAART) }\end{array}$ & $\begin{array}{l}\text { HIV+ adults starting or who } \\
\text { recently started HAART }\end{array}$ & $\begin{array}{l}\text { Peer-provided directly observed therapy and support to increase } \\
\text { adherence to highly active antiretroviral therapy (HAART) }\end{array}$ \\
\hline Mujer Segura, Healthy Woman & Female sex workers ages $18+$ & A single session program to increase use of condoms \\
\hline $\begin{array}{l}\text { A Peer Education Program for } \\
\text { Taxicab/Tricycle Drivers and Other } \\
\text { Bridge Populations }\end{array}$ & $\begin{array}{l}\text { Transportation industry } \\
\text { workers, other bridge } \\
\text { populations }\end{array}$ & $\begin{array}{l}\text { A peer educator program to reduce sexual risk behaviors among } \\
\text { members of bridge populations who are at risk of spreading STIs/HIV }\end{array}$ \\
\hline
\end{tabular}

Voluntary Counseling and Testing for

Female Sex Workers (VCT Program)

\section{HIV EBPs for US Youth}

A Clinic-Based AIDS Education Program for Female Adolescents

ABAN AYA Youth Project: $5^{\text {th }}$ Grade, $6^{\text {th }}$ Grade, $7^{\text {th }}$ Grade, $8^{\text {th }}$ Grade

Adolescents Living Safely: AIDS

Awareness, Attitudes and Actions

Adolescents Living Safely: AIDS

Awareness, Attitudes and Actions for

Gay, Lesbian and Bisexual Teens

AIDS Prevention for Adolescents in School

Female sex workers ages 18+

Pre-test counseling, STI/HIV testing, and post-test counseling

Sexually active girls ages $13-21$ A single-session group interventionon the transmission and prevention of HIV/AIDS

Youths in grades $5-8$

An Afrocentric social development curriculum deliveredover a four-year period

Runaway youths $11-18$ years

20 small group discussion sessions with case management and private counseling

LGBT youth ages $14-19$

Provides education, social and medical services, and peer support through case management, comprehensive health care, and risk assessment counseling with small group discussion sessions

High school students

A six-session programto improve knowledge, beliefs, self-efficacy, and risk behaviors concerning HIV/AIDS

AIDS Risk Reduction Education and Skills Training Program (ARREST)

AIDS Risk Reduction for College $\underline{\text { Students }}$

Teens ages $12-16$

College students

$\underline{\text { ASSESS for Adolescent Risk Reduction }}$

CyberSenga

FOCUS: Preventing Sexually

Transmitted Infections and Unwanted

Pregnancies among Young Women

HORIZONS: STI/HIV Sexual Risk

Reduction Intervention for African

American Girls

Information-Motivation-Behavioral

Skills HIV Prevention Program (IMB)

Keepin' It R.E.A.L.! A

Mother-Adolescent HIV Prevention

Program

their mothers
A three-session small group program on reducing adolescent health-risk behaviors

Three sessions with information, motivation, and behavioral strategies for AIDS risk reduction

Provides tools to enhance risk-reduction communication from health care providers

A five-module online HIV prevention program

A four-session group intervention addressing prevention of sexually transmitted infections (STIs) and unintended pregnancies

AA adolescent girls seeking sexual health services

A two-session STI/HIV sexual risk reduction program for small groups

High school students

Adolescents ages $11-14$ and
A four-session classroom intervention to reduce high school students' risk of HIV infection

A seven-session social-cognitive HIV prevention intervention 


\section{Continued}

Multimedia SiHLE

Prime Time: A Positive Youth $\underline{\text { Development Program }}$

Poder Latino: A Community AIDS Prevention Program for Inner-City Latino Youth

Queens Hospital Center's Teenage Program

Reach for Health: A School-Sponsored

Community Youth Service Intervention AA, HIS youth grades 5 - 8 for Middle School Students

Reproductive Health Counseling for Young Men

Rikers Health Advocacy Program $\underline{\text { (RHAP) }}$

\section{$\underline{\text { Safer Sex Efficacy Workshop }}$}

$\underline{\text { Safer Sex Intervention }}$

School-Linked Reproductive Health Services (The Self Center)

Sexual Health and Adolescent Risk Prevention (SHARP)

SiHLE: Health Workshops for Young Black Women

Teen Health Project (THP): Community-Level HIV Prevention Intervention for Adolescents in Low Income Housing Development

$\underline{\text { Youth AIDS Prevention Project (YAPP) }}$

Youth and AIDS Project's HIV

Prevention Program

\section{HIV EBPs for US Adults}

AIDS Prevention and Health Promotion among Women

$\underline{\text { Brother to Brother }}$

Doing Something Different

Focus on the Future

Holistic Health Recovery Program for Injection Drug Users (HHRP)

Holistic Health Recovery Program for Injection Drug Users Living with HIV $\underline{\text { (HHRP+) }}$

AA adolescent girls

HIS youth ages $14-20$

Pregnant adolescents

Boys ages $15-18$ drug users 16 - 18

College students an STI

Adolescents

AA adolescent girls

Adolescents in low income housing

AA youth grades $5-8$

GB males ages 13 - 21

Women ages 16 - 29

AA, GB men 30 s drug users drug users
Sexually active adolescent girls

Incarcerated male adolescent

Young women ages 13 - 23 with An individualized STI intervention program to reduce high-risk sexual behaviors

Middle and high school students A program combining education, counseling, and reproductive services An interactive single-session intervention targeting both substance use and sexual risk reduction

Health workshops addressing STI/HIV/AIDS prevention needs

A community-level HIV prevention intervention

Adults in their mid-20s to early

AA men living with STI/HIV

HIV-negative adult injection

HIV-positive adult injection

An interactive, computer-based intervention addressing HIV/AIDS and STI prevention needs

An 18-month multicomponent program that seeks to reduce sexual risk behaviors, violence involvement, and school disconnection

A multifaceted community AIDS prevention program for high-risk inner-city youth

A clinic-based program providing medical care, psychosocial support, and education to the adolescent, her partner, and her family

A school-sponsored community youth service intervention for middle school students, combining a classroom teaching component with community service work

A one-hour, single-session, clinic-based intervention

Four one-hour small group sessions focusing on health education issues, particularly HIV/AIDS

A single three-hour session to increase self-efficacy to prevent A single three-hour session

STDs, HIV/AIDS, and substance abuse prevention among high-risk students

Provides education, peer support, counseling, and case management to males at high risk for HIV/AIDS

A four-session group program on developing and following a sound sexual health plan

A three-session behavioral intervention aimed at reducing HIV infection

A single session intervention to promote condom use in health clinics

A safer sex intervention for recently diagnosed individuals

A 12-session group therapy intervention for HIV prevention through behavioral change

A 12-session group therapy intervention for harm reduction and health promotion 


\section{Continued}

HoMBReS: Hombres Manteniendo

Bienestar y RelacionesSaludables

(Men Maintaining Wellbeing and

Healthy Relationships)

Hot, Healthy, and Keeping it Up!

Let's Chat

Multimedia WiLLOW: HIV

Transmission Reduction Among African AA women living with HIV American Women Living with HIV

Optimizing Partner Notification (OPeN) Adults with an STI, especially urban, minority populations

$\underline{\text { Point for Point }}$

Injection drug users

$\underline{\text { Portland Women's Health Program }}$

Recently incarcerated women

Project SAFE (P-SAFE)

HIS women

Project SAFE: Sexual Awareness For

Everyone An Intervention to Prevent

$\underline{\text { STDs Among Minority Women }}$

Project SMART: AIDS Education for

Drug Users in Short-Term Treatment

$\underline{\text { Protect and Respect }}$

$\underline{\text { Real Men Are Safe (REMAS) }}$

Real Talk

$\underline{\text { Safety Point }}$

SAHARA: Sistas Accessing HIV/AIDS

Resources At a click

The SISTA Project

SMART Couples

$\underline{\text { Sniffer }}$

Study to Reduce Intravenous Exposures (STRIVE)

Turning Point

WILLOW: HIV Transmission Reduction Among Women Living with HIV

\section{AA, HIS women}

Adults in in-patient and residential drug/ alcohol treatment facilities

Women living with HIV

Adult male substance abuse treatment center attendees

\section{AA, GB men}

Injection drug users

AA women ages $18-29$

AA women ages $18-29$

HIV serodiscordant couples

Intranasal drug users

Hepatitis C (HCV)-positive injection drug users ages 18 - 35 Injection drug users and their sex partners
A community-based, behavioral intervention that aims to increase condom use and HIV testing

A three-hour, single session, culturally appropriate intervention

A four-session intervention addressing risk reduction and AIDS prevention

An interactive computer-based HIV transmission reduction intervention

A clinic-based patient-centered program, promotes STI partner notification

A needle exchange intervention designed for implementation in street settings

A program of 10 one-on-one sessions with a trained health specialist to reduce HIV risk behaviors and increase life stability

A computer-delivered HIV/STI prevention program with videos of individual women speaking candidly about HIV/STI-related topics, skills instruction, and role-play

A three session cognitive-behavioral intervention designed to reduce STIs

A two-session informational intervention and a six-session enhanced intervention including both information and behavioral skills training

A clinic-based behavioral intervention to reduce the sexual transmission of HIV

A group-level, clinic-based behavioral intervention designed to reduce HIV/STI risk

An online, multimedia, culturally appropriate sexual health promotion program

A community-based intervention that seeks to reduce sex- and drug-related HIV risk factors

An interactive, computer-based, culturally appropriate intervention for HIV risk reduction

A peer-led program to prevent HIV infection

A four-session interventionto increase antiretroviral therapy (ART) adherence

A four-sessions program about AIDS, drug use, sexual risk behavior, and drug abuse treatment

A group-level, clinic-based, behavioral intervention that aims to reduce 5 risky distributive injection practices

Two separate interventions designed to reduce the frequency and probability of injection-risk behavior

An HIV transmission reduction group intervention

${ }^{1}$ Abbreviations used for Target Populations: African American (AA), Asian and Pacific Islander (API), Hispanic (HIS), Lesbian/Gay/Bisexual/ Transgender (LGBT), Gay/Bisexual (GB). ${ }^{2}$ Additional information on all these programs can be found at https://www.socio.com/ or by clicking on the hyperlinked Program Name in the table. 
Table 2. Datasets in the Sociometrics Library with a topical focus on HIV/AIDS/STIs.

\section{DATASET NAME \\ Adolescent Decision-Making and \\ Contraceptive Behavior: San \\ Francisco, 1984-1986 \\ Adolescent Women's Contraceptive \\ City, 1988 \\ Alternative High School Youth Risk Behavior Study, 1998}

Decision Making Project, Baltimore 430 adolescent women

Behavioral Risk Factor Surveillance System (BRFSS) 1999, 2000, 2001, 2007, 2008, 2009, 2010, 2011, 2012, $\underline{2013}, \underline{2014}, \underline{2015}, \underline{2016}$

California Survey of AIDS Knowledge Attitudes \& Behavior 1987, 1988

Demographic, Behavioral \& Health Characteristics of Injection Drug Users in San Francisco 1985-86

Efficacy of a Standardized

Acupuncture Regimen and Amitriptyline Compared with Placebo as a Treatment for Pain Caused by Peripheral Neuropathy in HIV-Infected Patients, 1993-1997

Health Behavior Study of Detroit Minority Youth, 1991

Los Angeles Women's Health Risk Study, 1990

National AIDS Behavioral Surveys

(NABS), NABS I, Complete Sample, $\quad 13,785$ adults ages 18 - 75 1990-92

National AIDS Behavioral Surveys (NABS); NABS I, Poststratified separately to selected U.S. metropolitan cities: Chicago, Detroit, Houston, Los Angeles, Miami, New York, Philadelphia, 1990-92

National AIDS Behavioral Survey (NABS II), 1992

National Health and Social Life Survey, 1992

506 adolescents augmented data collection for

, gay-identifying men, multiple/high-risk partner drug users Francisco, California lower extremity peripheral neuropathy adolescents and young adults

1024 female street prostitutes 448 4480 adults ages $18-75$

5391 adults ages $18-75$

3432 adults ages $18-59$

\section{TARGET POPULATION ${ }^{1}$ \\ BRIEF DESCRIPTION ${ }^{2}$}

8918 students in grades $9-12$

9532 - 506,467 adult US residents

2012 - 4661 adults in California; heterosexuals, and recreational

438 intravenous drug users in San

$250 \mathrm{HIV}$-infected patients with

1435 urban low income AA and HIS Study to evaluate AIDS knowledge, perception of risk, and risk
A study examining adolescents' decision-making regarding contraceptive use and its relation to their contraceptive and reproductive intentions and actual behavior

A six-month, longitudinal study to determine whether contraceptive use is associated with young women's social networks and attitudes towards pregnancy and contraception

A study on health-risk behaviors that result in the most significant mortality, morbidity, disability, and social problems

Health-related telephone surveys collecting state data about US residents regarding their health-related risk behaviors, chronic health conditions, and use of preventive services

A telephone survey for the purpose of forecasting the course of the AIDS epidemic and planning risk reduction programs

Data on demographic characteristics, sexual and other risk behaviors, and general health characteristics of intravenous drug users

A study to evaluate the efficacy of a standardized acupuncture regime and amitriptyline hydrochloride for relief of pain due to HIV-related peripheral neuropathy behaviors related to sex

Study of behavior linked to transmission of HIV and other STIs

Study on sexual practices, drug use, HIV antibody test seeking, and levels of AIDS-related knowledge, beliefs and social skills over the adult life-span

Study on sexual practices, drug use, HIV antibody test seeking, and levels of AIDS-related knowledge, beliefs, and social skills over the adult life-span

Study on sexual practices, drug use, HIV antibody test seeking, and levels of AIDS-related knowledge, beliefs and social skills over the adult life-span

Study on the extent to which sexual conduct and general attitudes toward sexuality are influenced by gender, age, marital status, and other demographic characteristics 


\section{Continued}

National Health Interview Survey on

Disability, Complete Phase I,

1994-1995, Complete Phase II,

1994-1995

National Sexual Health Survey

(NSHS), 1996

National Survey of Adolescent

Males-1988 and 1990-91

National Survey of Family Growth,

Cycle III (Women Aged 15-19), 1982,

Cycle III (Women Aged 15-44), 1982,

Cycle III Exposure Interval File, 1982, 76

Cycle IV, 1988, Cycle IV, 1988 and ages 15 - 44

1990, Telephone Reinterview,

Cycle 5, 1995, Cycle 6, 2002,

2006-2010, 2011-2013, 2013-2015

$\underline{\text { National Survey of Men, } 1991}$

3321 men ages $20-39$

National Survey of Women, 1991

1669 women ages $20-29$

$\underline{\text { NOD/Harris Survey of Americans }}$ with Disabilities, 1998

Oakland County, Michigan Contraceptive Self-Care Study, 1987-1989

Prospero Project Condom Study, San 552 male sex workers in San Francisco, 1989-1991

30,598 HIV-infected and high-risk

Care and Health, 1996-2000

Social Influences on the Sexual Behavior of Youth at Risk for HIV Exposure, 1992

State and City Data on Adolescent Fertility, 1970-2001

Urban Mens Health Survey (UMHS), 2881 men who have sex with men $\underline{1997-98}$

300 AA children ages 9 - 15 living

Youth Risk Behavior Survey (YRBS) $\underline{1992}, \underline{1993}, \underline{1995}, \underline{1997}, \underline{1999}, \underline{2001}$, $\underline{2003}, \underline{2005}, \underline{2007}, \underline{2009}, \underline{2011}, \underline{2013}$, 2015, 2017 Francisco, CA HIV uninfected adolescents ages $12-18$ (MSM) in public housing developments

216 adolescent and young adult women

360 first-time patients at family planning clinics

10,645 - 16,410 students grades $9-12$
A continuous assessment and analysis of health trends in the United States

Study to assess a wide range of HIV-related and human sexuality topics

A two-wave, longitudinal study following young men from adolescence into young adulthood
Study on issues related to sexual behavior and condom use

Study examining sexual, contraceptive, and fertility behaviors, along with factors affecting those behaviors

A national study of attitudes and experiences of disabled persons

A study analyzing the prevalence and determinants of the quality of contraceptive use after a first visit to a family planning clinic

Data from face-to-face interviews to gather detailed information about the conditions (e.g., type of partner, type of sexual activity) under which condoms were and were not used

An observational study designed to better understand HIV disease progression and co-morbidity in adolescents

Data on social support, parental supervision, perceived risk exposure, and self-reported behavior and feeling

A compilation of secondary data on adolescent and young women's fertility

A telephone interview on sexual and HIV-related issues

An epidemiologic surveillance system to monitor the prevalence of youth behaviors that most influence health

${ }^{1}$ Abbreviations used for Target Populations: African American (AA), Asian and Pacific Islander (API), Hispanic (HIS), Lesbian/Gay/Bisexual/ Transgender (LGBT), Gay/Bisexual (GB). ${ }^{2}$ Additional information on all these programs can be found at https://www.socio.com/ or by clicking on the hyperlinked Program Name in the table. 
Table 3. Capacity-building tools for HIV professionals in the Sociometrics Library.

\begin{tabular}{|c|c|}
\hline RESOURCE NAME & BRIEF DESCRIPTION \\
\hline \multicolumn{2}{|c|}{ GENERAL TOOLS AND RESOURCES } \\
\hline Adolescent Sexual Health Resources & $\begin{array}{l}\text { A series of five science-based resources on adolescent sexual health, including a factual handbook, } \\
\text { HIV/AIDS teaching kit, and activity sourcebook }\end{array}$ \\
\hline $\begin{array}{l}\text { The Abstinence and Contraception } \\
\text { Education Storehouse (ACES) }\end{array}$ & $\begin{array}{l}\text { An online library of multimedia activities and exercises that can be used to enhance behavioral skills } \\
\text { training in teen sexual risk reduction interventions }\end{array}$ \\
\hline $\begin{array}{l}\text { HIV RAP (Research and Practice) } \\
\text { Interactive }\end{array}$ & $\begin{array}{l}\text { A collection of interactive, multimedia, science-based HIV information, prevention resources, and personal } \\
\text { stories }\end{array}$ \\
\hline $\begin{array}{l}\text { HIV/AIDS Prevention Practitioner } \\
\text { Institute (HPPI) }\end{array}$ & $\begin{array}{l}\text { Five interactive, multimedia, computer-delivered courses (and accompanying texts) designed to increase } \\
\text { capacity to plan, evaluate, and sustain effective HIV prevention interventions }\end{array}$ \\
\hline
\end{tabular}

Know the Risks (KTR): An

Interactive HIV/AIDS

Information and Personal

Risk Assessment Center

A computer-based sexual health and HIV/AIDS prevention education application

Know the Risks/Sexual Health Over A computer-based sexual health and HIV/AIDS prevention education application targeting adults aged 50 $\underline{50(\text { KTR50) }}$ and older

PETRA: Promoting Education, Training \& Research on AIDS

Easy-to-navigate, easy-to-understand online resource modules designed to increase understanding of the social and behavioral aspects of the HIV/AIDS epidemic

Tools for Building Culturally Competent HIV Prevention

Programs (CC)

An interactive website to help HIV prevention professionals who are planning, implementing, or evaluating programs to increase the cultural competence and effectiveness of HIV prevention efforts

\section{TRAINING MODULES FOR SPECIFIC EBPS}

$\underline{\text { FOCUS Training Modules }}$

$\underline{\text { HORIZONS Training Modules }}$

$\underline{\text { mDOT Training Modules }}$

Multimedia WiLLOW Training

Modules

Rikers Health Advocacy Program (RHAP) Training Modules

$\underline{\text { SAHARA Training Modules }}$

$\underline{\text { Sexual Health and Adolescent }}$ Risk Prevention (SHARP)

Training Modules

Teen Health Project (THP)

Training Modules
A series of eight interactive modules providing training on how to implement the intervention FOCUS: Preventing Sexually Transmitted Infections and Unwanted Pregnancies among Young Women

A series of six interactive modules providing training on how to implement HORIZONS: an STI/HIV Sexual Risk Reduction Intervention for African American Girls

A series of eight interactive modules providing training on how to implement the mDOT Program: For Individuals Receiving Highly Active Antiretroviral Therapy (HAART)

A series of eight interactive modules providing training on how to implement the intervention Multimedia WiLLOW: HIV Transmission Reduction Among African American Women Living with HIV

A series of six interactive modules providing training on how to implement the Rikers Health Advocacy Program (RHAP)

A series of six interactive modules providing training on how to implement the intervention SAHARA: Sistas Accessing HIV/AIDS Resources At a click

A series of nine interactive modules providing training on how to implement the intervention Sexual Health and Adolescent Risk Prevention (SHARP)

A series of eight interactive modules providing training on how to implement the Teen Health Project (THP): Community-Level HIV Prevention Intervention for Adolescents in Low Income Housing Development

behavior; attitudes and beliefs regarding sexual behavior; HIV/AIDS-related knowledge, attitudes, behaviors, and serostatus; current and past episodes of STIs; and other high-risk behaviors, including alcohol/drug use and prostitution. Included for each dataset are the raw data in ASCII and CSV format, question- 
naires, codebooks, frequencies, and SPSS and SAS analytic statements for statistical analysis of datasets. Many different papers have been written analyzing the datasets in Table 2, with various findings. These papers are not included in the Sociometrics Library, but can be readily found on databases such as PubMed and Google Scholar.

\subsubsection{Capacity-Building Tools for HIV Professionals}

The Sociometrics Library offers 16 capacity-building tools aimed at HIV professionals. These resources aim to increase the capacity of HIV educators and prevention providers to adapt, implement, and evaluate HIV prevention programs successfully. Some focus on specific HIV-related EBPs, while others focus on HIV risk reduction more generally. Some are offered in PDF format and others in interactive, multimedia format. Table 3 details the capacity-building resources for HIV professionals available in the Sociometrics Library.

\subsection{Access}

The evidence-based HIV/AIDS EBPs, datasets, and capacity-building tools in Tables 1-3 above can be accessed through individual, group, and institutional subscriptions (contact jjcard@socio.com for access information). Individual subscriptions allow a single health professional or practitioner to access, view, and administer one or more Library resources $24 / 7$ from their computer, tablet, or smartphone. Group subscriptions allow a team of health professionals, researchers, and educators access, view and administration privileges. A group administrator can purchase access for team members and manage access centrally. Finally, an institutional all-access pass can be purchased by community-based organizations, hospitals and health clinics, universities, public health departments, and other interested institutions. This institutional all-access pass grants access to the entire resource library of $400+$ EBPs, datasets, and capacity-building tools in https://www.socio.com/.

\section{Discussion}

The Sociometrics Library is a significant step forward in meeting the research-to-practice needs of frontline HIV prevention practitioners. In order to have a positive impact in the real-world, this library was built on the latest scientific knowledge, duly translated into formats accessible to global workers trying to stem the epidemic. The Sociometrics Library has many innovations, all aimed at facilitating real-world impact:

1) Identification and archiving of HIV prevention programs that science has found to be efficacious in reducing behaviors putting one at risk of HIV transmission. The collection of these validated prevention programs in one place saves health professionals valuable time and costs otherwise spent remaining up-to-date on the prevention literature and seeking out ways to access complete versions of the effective curriculum and implementation materials. The Sociometrics Library of replication-ready resources simplifies 
a process that currently presents a significant barrier to the use of evidence-based programs by HIV prevention practitioners.

2) Identification and archiving of datasets that science has found to be of high technical merit. The collection of the exemplary HIV/AIDS datasets in one place saves health researchers valuable time and costs otherwise spent remaining up-to-date on the prevention literature and seeking out the best ways to access the data on which publications were based. The Sociometrics Library of analysis-ready raw data and documentation simplifies a process that currently presents a significant barrier to secondary analysis of exemplary data by HIV prevention researchers.

3) Digitization and organization of effective program implementation materials to facilitate global access via the Internet. This innovation allows formerly printed, hard-copy educational products to be accessed at low cost anytime, any place. Health educators can now access prevention programs live during program implementation from their computer, tablet, or mobile phone. The curricula and materials are organized in lesson-by-lesson sequence, enabling easy use of the materials in schools, community-based organizations, clinics and hospitals.

4) Provision of capacity-building tools. The Sociometrics Library also includes science-based capacity-building and professional education tools that directly address some of the most significant challenges that prevention practitioners face when applying science-based research. These tools assist with adaptation of evidence-based programs to local settings, while maintaining the core program elements underlying the program's effectiveness. Other tools describe how to appropriately evaluate prevention efforts and analyze research datasets.

5) Provision of online browsing, search, and filtering capabilities to improve users' ability to find and select relevant products. The Sociometrics Library not only gathers effective programs, datasets, and capacity-building tools in one place, but also enables easy search and navigation within the library itself. Keyword search and filter capabilities by topic, target population, and product type allow users to quickly and easily find the most relevant product(s) for their needs.

6) Provision of original evaluation instruments. In order to encourage re-evaluation of the efficacious programs in a new setting, the Sociometrics Library also includes the original evaluation instrument used to demonstrate the efficacy of each program. The instrument can be re-used as is, or modified for use in a new evaluation in a new setting. The Sociometrics Library also offers additional, generic resources for program evaluation. The family of evaluation instruments and resources supporting each effective program facilitates re-evaluation in a new setting, to test the robustness of the initial finding of efficaciousness in the original site and to improve future implementations in the local site.

7) Scalable design. The Sociometrics Library was built with both scalable de- 
sign and a technological infrastructure for ease of future expansion, as other effective programs, datasets, and capacity-building tools are identified. The innovative technological platform allows for the upload and distribution of a wide variety of product and file types, including increasingly common multimedia products.

\section{Conclusion}

The Sociometrics Social, Behavioral, and Health Sciences Library at https://www.socio.com/ is a rich and innovative source of exemplary HIV/AIDS evidence-based programs (EBPs), datasets, and capacity-building tools for the continued professional education of HIV professionals. With several new innovations in prevention programming - such as low cost $24 / 7$ access to all facilitator, student, and evaluation materials comprising a diverse set of effective HIV/AIDS prevention programs; and "responsive design" for use on computers, tablets, and smartphones-the Sociometrics Library facilitates research as well as EBP uptake, implementation, and evaluation across a range of settings, including schools, clinics, community-based organizations, universities, global settings, low-resource settings, and settings with specific minority populations that have shouldered the brunt of the HIV epidemic.

\section{Conflicts of Interest}

The authors declare no conflicts of interest regarding the publication of this paper.

\section{References}

[1] White House Office of National AIDS Policy (2015) National HIV/AIDS Strategy for the United States: Updated to 2020.

https://www.aids.gov/federal-resources/national-hiv-aids-strategy/nhas-update.pdf

[2] Centers for Disease Control and Prevention (CDC) (2015) HIV among Hispanics/Latinos.

http://www.cdc.gov/hiv/pdf/group/racialethnic/hispaniclatinos/cdc-hiv-latinos.pdf

[3] Centers for Disease Control and Prevention (CDC) (2016) HIV and AIDS among African Americans.

http://www.cdc.gov/hiv/pdf/group/racialethnic/africanamericans/cdc-hiv-africana mericans.pdf

[4] UNAIDS (2017) UNAIDS Data 2017.

http://www.unaids.org/sites/default/files/media_asset/20170720_Data_book_2017_e $\underline{\text { n.pdf }}$

[5] Centers for Disease Control and Prevention (CDC) (2017) Diagnoses of HIV Infection in the United States and Dependent Areas, 2016. HIV Surveillance Report, 28.

[6] Kegeles, S.M., Rebchook, G., Pollack, L., Huebner, D., Tebbetts, S., Hamiga, J., Sweeney, D. and Zovod, B. (2012) An Intervention to Help Community-Based Organizations Implement an Evidence-Based HIV Prevention Intervention: The Mpowerment Project Technology Exchange System. American Journal of Commu nity Psychology, 49, 182-198. 
[7] Centers for Disease Control and Prevention (CDC) (2011) Compendium of Evidence-based HIV Behavioral Interventions. HIV Prevention Research Synthesis Project.

https://www.cdc.gov/hiv/research/interventionresearch/compendium/index.html

[8] Centers for Disease Control and Prevention (CDC) (2014) Community-Based Program to Prevent HIV/STD Infection among Heterosexual Black Women. MMWR, 63, 15-20.

[9] Ciaranello, A., Sohn, A.H., Collins, I.J., Rothery, C., Abrams, E.J., Woods, B., et al. (2018) Simulation Modeling and Metamodeling to Inform National and International HIV Policies for Children and Adolescents. Journal of Acquired Immune Deficiency Syndromes (1999), 78, S49-S57.

[10] Krishnaratne, S., Hensen, B., Cordes, J., Enstone, J. and Hargreaves, J.R. (2016) Interventions to Strengthen the HIV Prevention Cascade: A Systematic Review of Reviews. Lancet HIV, 3, e307-e317. https://doi.org/10.1016/S2352-3018(16)30038-8

[11] Marlin, R.W., Young, S.D., Bristow, C.C., Wilson, G., Rodriguez, J., Ortiz, J., Mathew, R. and Klausner, J.D. (2014) Piloting an HIV Self-Test Kit Voucher Program to Raise Serostatus Awareness of High-Risk African Americans, Los Angeles. BMC Public Health, 14, 1226. https://doi.org/10.1186/1471-2458-14-1226

[12] Alistar, S.S., Owens, D.K. and Brandeau, M.L. (2014) Effectiveness and Cost Effectiveness of Oral Pre-Exposure Prophylaxis in a Portfolio of Prevention Programs for Injection Drug Users in Mixed HIV Epidemics. PLoS ONE, 9, e86584. https://doi.org/10.1371/journal.pone.0086584

[13] Centers for Disease Control and Prevention (CDC) (2008) Compendium of HIV Prevention Interventions with Evidence of Effectiveness. https://www.cdc.gov/hiv/pdf/research/interventionresearch/rep/prevention_researc h_compendium.pdf

[14] Kelly, J.A. and Kalichman, S.C. (2002) Behavioral Research in HIV/AIDS Primary and Secondary Prevention: Recent Advances and Future Directions. Journal of Consulting and Clinical Psychology, 703, 626-639.

https://doi.org/10.1037/0022-006X.70.3.626

[15] Lyles, C.M., Kay, L.S., Crepaz, N., Herbst, J.H., Passin, W.F., Kim, A.S., Rama, S.M., Thadiparthi, S., DeLuca, J.B. and Mullins, M.M., The HIV/AIDS Prevention Research Synthesis Team (2007) Best-Evidence Interventions: Findings from a Systematic Review of HIV Behavioral Interventions for US Populations at High Risk, 2000-2004. American Journal of Public Health, 97, 133-143. https://doi.org/10.2105/AJPH.2005.076182

[16] Noar, S.M. (2008) Behavioral Interventions to Reduce HIV-Related Sexual Risk Behavior: Review and Synthesis of Meta-Analytic Evidence. AIDS Behavior, 13, 335-353. https://doi.org/10.1007/s10461-007-9313-9

[17] Parry, C.D.H., Carney, T. and Petersen Williams, P. (2017) Reducing Substance Use and Risky Sexual Behaviour among Drug Users in Durban, South Africa: Assessing the Impact of Community-Level Risk-Reduction Interventions. Journal of Social Aspects of HIVI AIDS Research Alliance, 14, 110-117.

https://doi.org/10.1080/17290376.2017.1381640

[18] Herbst, J.H., Sherba, R.T., Crepaz, N., Deluca, J.B., Zohrabyan, L., Stall, R.D. and Lyles, C.M. (2005) A Meta-Analytic Review of HIV Behavioral Interventions for Reducing Sexual Risk Behavior of Men Who Have Sex with Men. Journal of Acquired Immune Deficiency Syndromes, 39, 228-241.

[19] Johnson, W.D., Hedges, L.V. and Diaz, R.M. (2007) Interventions to Modify Sexual 
Risk Behaviors for Preventing HIV Infection in Men Who Have Sex with Men (Review). Cochrane Database of Systematic Reviews, No. 1, 1-18.

[20] Johnson, W.D., Diaz, R.M., Flanders, W.D., Goodman, M., Hill, A.N., Holtgrave, D., Malow, R. and McClellan, W.M. (2008) Behavioral Interventions to Reduce Risk for Sexual Transmission of HIV among Men Who Have Sex with Men. Cochrane Database of Systematic Reviews, No. 3, CD001230. https://doi.org/10.1002/14651858.CD001230.pub2

[21] Copenhaver, M.M., Johnson, B.T., Lee, I., Harman, J.J. and Carey, M.P. (2006) Behavioral HIV Risk Education among People Who Inject Drugs: Meta-Analytic Evidence of Efficacy. Journal of Substance Abuse Treatment, 31, 163-171. https://doi.org/10.1016/j.jsat.2006.04.002

[22] Strathdee, S. A., Shoptaw, S., Dyer, T.P., Quan, V. M., Aramrattana, A. and the Substance Use Scientific Committee of the HIV Prevention Trials Network (2012) Towards Combination HIV Prevention for Injection Drug Users: Addressing Addictophobia, Apathy and Inattention. Current Opinion in HIV and AIDS, 7, 320-325. https://doi.org/10.1097/COH.0b013e32835369ad

[23] Robin, L., Dittus, P., Whitaker, D., Crosby, R., Ethier, K., Mezoff, J., Miller, K. and Pappas-Deluca, K. (2004) Behavioral Interventions to Reduce Incidence of HIV, STD, and Pregnancy among Adolescents: A Decade in Review. Journal of Adolescent Health, 34, 3-26. https://doi.org/10.1016/S1054-139X(03)00244-1

[24] Crepaz, N., Horn, A.K., Rama, S.M., Griffin, T., Deluca, J.B., Mullins, M.M. and Aral, S.O. (2007) The Efficacy of Behavioral Interventions in Reducing HIV Risk Sex Behaviors and Incident Sexually Transmitted Disease in Black and Hispanic Sexually Transmitted Disease Clinic Patients in the United States: A Meta-Analytic Review. Sexually Transmitted Diseases, 34, 319-332.

[25] Senn, T.E. and Carey, M.P. (2008) HIV, STD, and Sexual Risk Reduction for Individuals with Severe Mental Illness: Review of the Intervention Literature. Current Psychiatry Reviews, 4, 87-100. https://doi.org/10.2174/157340008784529313

[26] Vu, L., Nieto-Andrade, B., Di Vincenzo, A., Rivas, J., Firestone, R., Wheeler, J. and Lungo, S. (2015) Effectiveness of Behavior Change Communications for Reducing Transmission Risks among People Living with HIV in 6 Countries in Central America. AIDS and Behavior, 19, 1203-1213.

https://doi.org/10.1007/s10461-014-0910-0

[27] Wilson, D. (2015) HIV Programs for Sex Workers: Lessons and Challenges for Developing and Delivering Programs. PLoS Medicine, 12, e1001808. https://doi.org/10.1371/journal.pmed.1001808

[28] Alford, S., Cheetham, N. and Hauser, D. (2005) Science \& Success in Developing Countries: Holistic Programs That Work to Prevent Teen Pregnancy, HIV \& Sexually Transmitted Infections. Advocates for Youth, Washington DC.

[29] Paul-Ebhohimhen, V.A., Poobalan, A. and van Teijlingen, E.R. (2008) A Systematic Review of School-Based Sexual Health Interventions to Prevent STI/HIV in Sub-Saharan Africa. BMC Public Health, 8, 4. https://doi.org/10.1186/1471-2458-8-4

[30] Shahmanesh, M., Patel, V., Mabey, D. and Cowan, F. (2008) Effectiveness of Interventions for the Prevention of HIV and Other Sexually Transmitted Infections in Female Sex Workers in Resource Poor Setting: A Systematic Review. Tropical Medicine and International Health, 13, 659-679. https://doi.org/10.1111/j.1365-3156.2008.02040.x

[31] Centers for Disease Control and Prevention CDC (2016) Replicating Effective Pro- 
grams. http://www.cdc.gov/hiv/research/interventionresearch/rep/index.html

[32] Martinez, O., Roth, A.M., Kelle, G., Downs, M. and Rhodes, S.D. (2014) Adaptation and Implementation of HoMBReS: A Community-Level, Evidence-Based HIV Behavioral Intervention for Heterosexual Latino Men in the Midwestern United States. AIDS Education and Prevention, 26, 68-80.

[33] USAID (2013) USAID's Implementation Science Investment: Improving HIV/AIDS Programming through the Translation of Research to Practice.

https://www.usaid.gov/news-information/fact-sheets/usaids-implementation-scienc e-investment

[34] World Health Organization (WHO) (2016) HIV Prevention, Diagnosis, Treatment and Care for Key Populations: Consolidated Guidelines.

http://apps.who.int/iris/bitstream/handle/10665/258967/WHO-HIV-2017.05-eng.p df? sequence $=1$

[35] Card, J.J., Solomon, J. and Cunningham, S.D. (2011) How to Adapt Effective Programs for Use in New Contexts. Health Promotion Practice, 12, 25-35. https://doi.org/10.1177/1524839909348592

[36] Dolcini, M.M., Gandelman, A.A., Vogan, S.A., Kong, C., Leak, T.N., King, A.J., DeSantis, L. and O'Leary, A. (2010) Translating HIV Interventions into Practice: Community-Based Organizations' Experiences with the Diffusion of Effective Behavioral Interventions (DEBIs). Social Science \& Medicine, 71, 1839-1846. https://doi.org/10.1016/j.socscimed.2010.08.011

[37] Kelsey, M. and Layzer, J. (2014) Implementing Three Evidence-Based Program Models: Early Lessons from the Teen Pregnancy Prevention Replication Study. Journal of Adolescent Health, 54, S45-S52. https://doi.org/10.1016/j.jadohealth.2013.12.024

[38] Leeman, J., Calancie, L., Kegler, M.C., Escoffery, C.T., Herrmann, A.K., Thatcher, E., Hartman, M.A. and Fernandez, M.E. (2017) Developing Theory to Guide Building Practitioners' Capacity to Implement Evidence-Based Interventions. Health Education \& Behavior, 44, 59-69. https://doi.org/10.1177/1090198115610572

[39] Jones, D., Weiss, S. and Chitalu, N. (2015) HIV Prevention in Resource Limited Settings: A Case Study of Challenges and Opportunities for Implementation. International Journal of Behavioral Medicine, 22, 384-392. https://doi.org/10.1007/s12529-014-9397-3

[40] Dévieux, J.G., Malow, R.M., Rosenberg, R. and Dyer, J.G. (2004) Context and Common Ground: Cultural Adaptation of an Intervention for Minority HIV Infected Individuals. Journal of Cultural Diversity, 11, 49-57.

[41] Vinh-Thomas, P., Bunch, M.M. and Card, J.J. (2003) A Research-Based Tool for Identifying and Strengthening Culturally Competent and Evaluation-Ready HIV/AIDS Prevention Programs. AIDS Education and Prevention, 15, 481-498. https://doi.org/10.1521/aeap.15.7.481.24050

[42] Chen, E.K., Reid, M.C., Parke, S.J. rand Pillemer, K. (2013) Tailoring Evidence-Based Interventions for New Populations a Method for Program Adaptation through Community Engagement. Evaluation \& the Health Professions, 36, 73-92.

[43] Kemp, L. (2016) Adaptation and Fidelity: A Recipe Analogy for Achieving both in Population Scale Implementation. Prevention Science, 17, 429-438. https://doi.org/10.1007/s11121-016-0642-7

[44] Veniegas, R.C., Kao, U.H., Rosales, R. and Arellanes, M. (2009) HIV Prevention Technology Transfer: Challenges and Strategies in the Real World. American Journal of Public Health, 99, S124-S130. 
[45] Gandelman, A. and Rietmeijer, C.A. (2004) Translation, Adaptation, and Synthesis of Interventions for Persons Living with HIV: Lessons from Previous HIV Prevention Interventions. Journal of Acquired Immune Deficiency Syndromes, 37, S126-S129. https://doi.org/10.1097/01.qai.0000140612.89757.8a

[46] Solomon, J., Card, J.J. and Malow, R.M. (2006) Adapting Efficacious Interventions: Advancing Translational Research in HIV Prevention. Evaluation and the Health Professions, 29, 162-194. https://doi.org/10.1177/0163278706287344

[47] Rotheram-Borus, M.J., Swendeman, D., Flannery, D., Rice, E., Adamson, D.M. and Ingram, B. (2009) Common Factors in Effective HIV Prevention Programs. AIDS and Behavior, 13, 399-408. https://doi.org/10.1007/s10461-008-9464-3

[48] Galbraith, J.S., Stanton, B., Boekeloo, B., King, W., Desmond, S., Howard, D., Black, M.M. and Carey, J.W. (2009) Exploring Implementation and Fidelity of Evidence-Based Behavioral Interventions for HIV Prevention: Lessons Learned from the Focus on Kids Diffusion Case Study. Health Education and Behavior, 36, 532-549. https://doi.org/10.1177/1090198108315366

[49] Gill, S., Kuwahara, R. and Wilce, M. (2016) Through a Culturally Competent Lens: Why the Program Evaluation Standards Matter. Health Promotion Practice, 17, 5-8. https://doi.org/10.1177/1524839915616364

[50] Kegeles, S.M., Rebchook, G.M. and Tebbetts, S. (2005) Challenges and Facilitators to Building Program Evaluation Capacity among Community-Based Organizations. AIDS Education and Prevention, 17, 284-299. https://doi.org/10.1521/aeap.2005.17.4.284

[51] Van Koperen, T.M., Renders, C.M., Spierings, E.J.M., Hendriks, A.-M., Westerman, M.J., Seidell, J.C. and Schuit, A.J. (2016) Recommendations and Improvements for the Evaluation of Integrated Community-Wide Interventions Approaches. Journal of Obesity, 2016, Article ID: 2385698. 